\title{
MEASURING QUALITY OF THE SERVICES PROVIDED BY THE COMMERCIAL WEB SITES
}

\author{
Professor PhD Filimon Stremțan, ,1 Decembrie 1918” University of Alba Iulia, \\ e-mail:filimon_stremtan@yahoo.com \\ Lecturer PhD Andreea Muntean, ,1 Decembrie 1918” University of Alba Iulia, \\ e-mail: bologandreea@yahoo.com
}

\begin{abstract}
The increasingly systematic usage of Internet in the decisional process of the consumers determines the vendors to apply more frequently to the advantages of this instrument. A site must be before of all capable to answer the expectances of the consumers to which it addresses. The researchers identified a number of criteria that the consumers have in view when they evaluate the Web sites in general and especially the quality of services they provide.
\end{abstract}

Keywords: Internet, electronic services quality, online shopping, electronic commerce

JEL Codes: M31

Even if it is still relatively recent, buying online is becoming a daily shopping method. According to a GECAD ePayment study, in Romania in 2007 electronic commerce has reached a 30 million Euros volume of transactions, with over 30\% more than in 2006.

\section{The quality of electronic services}

After more than 20 years, researches about the quality of traditional services allow a better knowledge of this concept; while the study of the services provided by web-sites is still in its early stages. It is defined as "the stage in which a web-site allows the storing, the buying and the efficient delivery of products" and refers to the transactional quality, which includes elements of testing before and after the experience in the perception of the accessed service.

By making a parallel with the quality of transactional services, we can show the similitude's and differences between these two concepts.

The most important and probably the most obvious difference between the quality of traditional services and the quality of online services is the replacement of the interpersonal interactions with the man - machine interaction. This relatively simple difference raises many questions about the type of dimensions which should be taken into consideration for the services' evaluation in the context of online commerce.

The characteristics of online commerce make the use of the dimensions of the services developed in the non-electronic commerce environment not to be adapted to web-sites or they do not to contain all the evaluation elements of the web-sites commercial services' quality.

The classic dimensions of the traditional services' quality are represented by tangible elements, like: reliability, reactivity, safety and empathy from the services' provider. Right now there isn't a consensus about the dimensions of the online services. A few dimensions were proposed in a describing manner, while others were proposed in a systematic manner: security/confidentiality, the site's design, effectiveness, the easiness of using a site, reliability, meeting deadlines in time, the information's quality.

Thus, the positive aspects (warmth, attachment) expressed in traditional services don't seem to manifest in the perception of electronic services. The negative aspects (anger, irritation, frustration) also don't seem as intense online as the ones expressed when having problems with 
traditional services. Finally, if the classic evaluations of the traditional services are based on a calculus of the difference between expectations and perceptions, it is difficult to use the same device to measure the quality of electronic services. The users had difficulties in formulating their own expectations regarding the quality of online services.

\section{Different ways to measure online services quality}

There are different ways to measure the quality of the services provided by a web-site. They can be classified in two large categories:

- behavioral measurements refer to the measurement of the site's commercial activity: the number of visits, the number of unique visitors or the new visitors' conversion percent, the log files analysis, or even the web-surfing protocol's analysis and the behavior's measurement technique which is very useful for the web-site's analysis.

- attitude measurements: the traditional scales allow the evaluation of the consumers' perceptions or the measurement of these perceptions by experts in the field.

Within these researches, the attitude perspective was not used in the measurement of electronic services.

Information about the existence of some studies has been published in the specialized literature, which makes possible the perceptions' measurement regarding the quality of online services. These studies are:

- EtailQ, developed by Wolfinbarger and Gilly. This scale contains 14 items allotted on four dimensions (design, service for the consumer, reliability / meeting dead-lines and confidentiality / security of private life);

- Webqual 4, developed by Barnes and Vidgen. This scale is composed of 22 items on four dimensions (the information's quality, the interactivity's quality, trust and empathy, utility and design);

- Sitequal, developed by Yoo and Donthu, contains 9 items allotted on four dimensions (easiness of use, design, the fastness of the site's evolution and security);

- IRSQ was created by Swinder, Trocchia and Gwinnes and includes 22 items allotted on four dimensions (performance, accessibility, security, satisfaction and information). literature.

The research of the online services' quality is a field in full expansion in the specialized

\section{The criteria used by consumers when evaluation online services' quality}

The researches have identified a number of criteria which consumers take into consideration when evaluating a web-site in general and its services' quality in particular. These criteria are: the information's quality, how easy it is to surf the site, the design or the graphic style of the site, the procedures' reliability or meeting dead-lines in time, security and the respect for private life. These criteria were validated and maintained through semi-directives from buyers and experts.

(I) The information presented on the site - The quality and the quantity of information presented on a site are often mentioned as important arguments in the case of online shopping. One of the most important advantages of online shopping is the information's availability, which determines a reduction of the costs involved in searching information about the products. The online buyers prefer and appreciate the fact they can get information directly, without asking a seller; this way a connection is set between the consumer's capacity to look for information and the online environment, and the feelings of freedom and control rise. Chen and Wells showed that the information's dimension has a more important impact in the global evaluation of a web-site than its organizational dimension and its fun side. 
So, an important factor used as criteria when evaluating a site is providing enough information in order to compare the products and making the final decision. A commercial web-site must present visual and text information in a manner that is sufficiently clear and precise so the users have no problem understanding. The capacity to compare prices and the information's quality (accuracy, updating, credibility) leads to a growth of the relative satisfaction, of the buying experience and to the buying of the product, which rises the probability of revisiting the site and of shopping again. Furthermore, when the user can control the content, the duration (the time when the information is presented) and the information's succession regarding the product, the capacity of assimilation and memorizing also rises and the use of information is improved.

The quality and quantity of the information available on a web-site are not criteria that are directly researched in the evaluation of traditional services. An adequate and exact framework for information is considered a key element for the provided online service. The importance of this dimension can be explained through the lack of interaction with real salesmen, because in this case the buyer is forced to rely on his own abilities to locate and buy the desired products or services.

(II) The easiness of using a site - The online transactions seem to be complex and can intimidate many consumers. The easiness of using a site is an important element of electronic services. In the context of the Internet, the easiness of using the site on long term was called "employability". The employability in the physical world refers to the interior design of stores and to the easiness of walking through a store. For a web-site, employability means the way in which the user perceives and interacts with the site: is it easy to surf this site? The key elements which influence the employability of a site are: the site's search engine, the downloading speed of the web-pages and the way the site is organized. These elements influence the easiness of surfing the site and the framework of the efforts imposed for surfing and buying from a commercial web-site.

The surfing quality can facilitate or inhibit the surfing and buying behavior. This dimension was identified in a recurrent manner. It refers to the functional quality described by Gronroos. This dimension is specific for online sales and it differs from the classical dimensions of the traditional services' quality.

(III) The site's design - The design of a site refers to the richness of the environment's representation, which is determined by its form characteristics: its graphic, colors, the using of images, of symbols, animation, video features, dialog windows, etc. These elements contribute to creating the virtual atmosphere of the site. Researchers are interested in the graphic style's impact (color, photos, graphics, animations, etc) on the consumer's perception when buying online. Dreze and Zufryden have pointed out the fact that the conception of a web-site (the graphic look, the images' proportionality, the presence of animated images, the number of widows) has an impact on the consumer's behavior during his visit on the site (the time spent visiting the site and the number of visited pages). But, the more a site uses the multimedia possibilities offered by the Internet (graphics, sounds, animations, videos) the longer it takes to download, which can have a negative impact on the site's evaluation. Thus, a part of the efficaciousness' control can elude the designer, because it is directly tied to the quality of the connections and of the materials that each user has.

(IV) Reliability and honoring commitments - Another important element in evaluating the online services' quality is reliability.

In the traditional context, reliability is defined as "the ability of the services" provider to offer the promised product in an exact, precise and trust-worthy manner". Reliability is translated for a web-site by honoring the delivery conditions, the precision of the product's description and other aspects tied to honoring commitments. Reliability is closely linked to the online salesman's ability to keep his promises, to respect the trade terms (delivering the ordered product, offering the desired service, being on time with the delivery). Online salesmen must be competent and honest in order to meet the consumer's expectations. They must supervise orders and take orders for products or services $24 / 7$ throughout the year. The client must be able to do online transactions, to search for information regarding the ordering method, to choose the payment and delivery methods. 
In order to contribute to a better evaluation of the reliability, online sellers must provide the consumer along with the surfing and choosing instruments, contact options for the cases when a problem occurs or the buyer wants to ask a question (a delay or an error in the distribution). To the reliability of the provided information also contributes the updating frequency of the products and services and of the information regarding them.

In conclusion, online sellers must honor their commitments by rapidly correcting the errors and by ensuring the operations' punctuality.

(V) Security and respecting private life - "Safety" is the term used worldwide in traditional services in order to describe the consumer's feelings of security and trust.

In the framework of online commerce, safety is defined by the risks tied to security and private life. Security involves protecting the users from frauds and financial loss when they use their credit cards on a web-site. Respecting someone's private life refers to protecting their personal information and to forbidden taking and transmitting this information to other sites. This requires keeping the identity of the consumers anonymous and asking for permission before sending their private information (for free or for a sum of money). This dimension can seem unique in the context of online commerce. Because of the lack of interpersonal contact on the Internet, consumers grant a bigger importance to the security and confidentiality of online transactions. The policy of sites regarding the confidentiality of personal information and the security of payments contributes to the consumers' peace of mind and influences the quality of online shopping.

As a conclusion, consumers evaluate the quality of online services by relying on five dimensions. Thus, the formulating of the following hypotheses is possible:

1. The information provided by the site positively influences the evaluation of electronic services;

2. The easiness of surfing the site positively influences the evaluation of electronic services.

3. The site's design positively influences the evaluation of electronic services.

4. Reliability and honoring commitments positively influence the evaluation of electronic services.

5. The security of payments and the confidentiality of personal information positively influence the evaluation of electronic services.

\section{References}

1. Bressolles G.- La qualité de service électronique: NetQu@l, Proposition d'une échelle de mesure appliquée aux sites marchands et effets modérateurs, Recherche et Applications en Marketing

2. Bressolles G.- La qualité de service électronique, Netqu@l: Mesure, consequences et variables modératrices, Thése pour l'attitude du titre de Docteur és Sciences de Gestion, Université de Toulouse

3. Bressolles G., Nantel J. - La qualité de service électronique: rôle modérateur du type de biens vendus sur le site et impact sur l'attitude envers le site, Actes des journées Nantaises sur le ecommerce, CdRom.

4. Kotler, Ph., Armstrong, G., Principiile marketingului, Editura Teora, Bucureşti, 2006

4. Nantel J., Bressolles G. - Vers une Typologie des sites Web destinés aux consommateurs, Revue Française de Marketing

5. Parasuraman A., Grewal D. -The impact of Technology on the Quality -Value-Loyality Chain: A Research Agenda, Journal of The Academy Science, nr. 28

6. Parasuraman A., Zeithaml V.A, Berry L.L. - SERVQUAL : A Multiple-Item Scale for Measuring Consumer Perceptions of Service Quality, Journal of Retailing, nr.64

7. Parasuraman A., Zeithaml V.A et Malhotra A. - E-S-QUAL:A Multiple-Item Scale for Assessing Electronic Service Quality, Journal of Service Research, nr. 7 